\title{
Temporal dynamics between faculty goals, burnout/engagement, and performance in teaching and research: A latent change score approach
}

\author{
Martin Daumiller \\ University of Augsburg
}

\author{
Markus Dresel \\ University of Augsburg
}

\begin{abstract}
Motivation plays a central role in faculty members' professional lives - with achievement goals having been found to have important links with their burnout/engagement and performance. However, the few studies investigating these links were cross-sectional and considered only one of the two equally important work do- mains of faculty members. In the present research, we analyze the temporal relationships between achievement goals and burnout/engagement as well as performance and investigate domain specificity of goal pursuit by considering goals for teaching and for research. We conducted a longitudinal study (4 measurement points across two years) including 681 German faculty members. Multivariate Latent Change Score modeling attested that in both domains, mastery-approach goals were positively related to subsequent development of performance, while performance was also positively related to subsequent development of mastery goals, creating a double positive loop. Performance goals and work-avoidance goals were differentially associated with performance in both domains, indicating that the effects of goals can be bound to different contextual features. For overall burnout/ engagement, our results implied that primarily research goals mattered for its development (with performance- avoidance and work-avoidance goals being risk factors), while high burnout levels were associated with sub- sequent reduction of adaptive mastery-approach goals in both domains. This highlights the relevance of achievement goals for burnout/engagement and performance of faculty and illuminates their complex temporal dynamics that can also meaningfully inform achievement goal research in other contexts.
\end{abstract}

Keywords: Faculty, Goal, Motivation, Stress, Achievement

\begin{abstract}
C) 2022, Elsevier Inc. The official citation for this manuscript is: Daumiller, M., \& Dresel, M. (2022). Temporal dynamics between faculty goals, burnout/ engagement, and performance in teaching and research: A latent change score approach. Contemporary Educational Psychology, 72, 102134. Advanced online publication. https://doi.org/10. 1016/j.cedpsych.2022.102124. This paper is not the copy of record and may not exactly replicate the final, authoritative version of the article. The final article will be available, upon publication, via its DOI.
\end{abstract}

\section{Introduction}

Faculty well-being and performance are two central and intertwined variables within higher education that are highly relevant for society (e.g., through student outcomes, scientific progress, economic activity, and government decision making; see Landry et al., 2003;

\footnotetext{
Correspondence concerning this article should be addressed to Martin Daumiller, Department of Psychology, University of Augsburg, Universitätsstr. 10, 86135 Augsburg, Germany;

Martin.Daumiller@phil.uni-augsburg.de.

We have no known conflicts of interest to disclose.

The research reported in this article was supported by German Research Foundation Grant DA 2392/2-3 to Martin Daumiller and Grant DR 454/83 to Markus Dresel.
}

Perkmann et al., 2013; Weinberg et al., 2014). Motivation, in turn, is posited to be central for faculty members' professional experiences and performance. Among the different motivation frameworks that have been applied to faculty members, the achievement goal approach is especially prominent and focuses on the personal motivations of faculty members in the form of their achievement goals (Daumiller et al., 2020). In particular, their goals are posited to matter for how well they cope with work stressors and how well they perform: As achievement goals span up motivational systems that underly the perception and interpretation of achievement situations, the pursuit of different types of goals can be expected to affect the development of burnout experiences through different evaluations of objective stressors and the coping mechanisms used to 
deal with them (Daumiller \& Dresel, 2020a). With burnout experiences, we mean subjective perceptions of reactions to strain factors, subsuming psychological, physiological, and mental aspects. Such experiences are often tied to performance, which should also be affected by achievement goals through individuals choosing different tasks and pursuing them with different levels of commitment depending on their goals. Beyond these effects from goals on burnout experiences and performance over time, burnout experiences and performance might also affect goal setting processes (e.g., in times of high pressure, less resource-intensive goals are chosen; see also DeShon \& Gillespie, 2005). Studies have already provided preliminary, cross-sectional research findings supporting linkages between these constructs; however, these works do not allow for insights into the temporal dynamics between them, which we seek to disentangle in the present work. Further, prior investigations have independently focused on either the teaching or the research domain, while motivations are separable for these two central domains and may entail different effects between them (Daumiller \& Dresel, 2020b). Thus, we also consider the specificity of goal pursuit regarding these two domains to elucidate the temporal relationships between goals for teaching and research with burnout experiences and performance (see Figure 1 for a summary of the investigated constructs). Addressing these two issues is not only paramount for improving our theoretical understanding of the role of motivation for how one feels and performs in professional settings (which goals matter, and are they causes or consequences?), but also for insights into how to support faculty in terms of their wellbeing and upkeeping of performance. Moreover, the consideration of faculty - with the two domains of teaching and research within the same population-, allows to uncover how the role of goals may differ between different contexts, and how shifts in motivations between different domains may arise.

\subsection{Burnout/engagement, and Teaching and Re- search Performance of Faculty}

Faculty members may be quite susceptible to burnout experiences due to their wide array of tasks, high teaching and research demands, and relationships with large numbers of students, staff, and administrators (Blix et al., 1994). In fact, high stress and burnout levels are frequently reported by faculty members on an international level, such as in Australia (Winefeld et al., 2008), Canada (Catano et al., 2010), Germany (Teich- ler et al., 2013), South Africa (Barkhuizen \& Rothmann, 2008), UK (Kinman et al., 2006), and USA (Padilla \& Thompson, 2015). Burnout experiences of faculty should be of interest to higher education as a whole, as they are central for faculty well-being, are frequently intertwined with performance, and strongly contribute to faculty retention (Jakstat et al., 2012; Salimzadeh et al., 2020). Besides documenting high stress levels, past research has also indicated that inter-individual differences in burnout experiences are linked to differences in faculty motivation - beyond background factors, task demands, and stressors (e.g., Sabagh et al., 2018; Singh et al., 1998).

Professional stress is frequently labelled with the expression "burnout", a term introduced in the 1970s to describe a state of physiological and psychological strain (Freudenberger, 1974). Contemporary conceptualizations of burnout postulate that it can be viewed on a continuum from positive (engagement) to negative (burnout) poles concerning how one copes with work situations (Maslach \& Leiter, 2008), implying that individuals vary regarding these experiences. Accordingly, we use the term burnout/engagement to refer to these burnout levels that are understood as the subjective perceptions of reactions to objective strain factors, containing psychological, physiological, as well as mental aspects (in particular, subsuming the facets of emotional exhaustion, depersonalization, and reduced personal accomplishments; Maslach et al., 1996). Regarding faculty members in particular, it can be assumed that burnout/engagement constitutes a general factor that is composed of individual experiences in the domains of teaching and research (for a similar argument regarding occupational well-being, see Mudrak et al., 2018). While faculty members are also active in other domains, such as administration/service, teaching and research are the two core domains that shape their professional identity, and are thus highly relevant for faculty members' satisfaction and strain with their job (Daumiller \& Dresel, 2018). However, the extent to which individual achievement motivation in these two domains influences (or is influenced by) professional stress remains an open question.

Besides this overarching aspect of faculty well-being in their job, performance represents a central domain-specific construct for teaching and research - the core tasks of faculty (with teaching and research performance being typically only slightly correlated; Hattie \& Marsh, 1996). In particular, teaching performance is essential for the quality of student engagement, differences in their learning outcomes, and their persistence (BrckaLorenz et al., 2012; McKeachie, 
2007; Pascarella \& Terenzini, 2005; Umbach \& Wawrzynski, 2005), while research performance is crucial for scientific progress (e.g., Javitz et al., 2010). Teaching and research performance are thus fundamental for informed citizenship, scientific advancement, economic activity, and government decision-making (Perkmann et al., 2013; Weinberg et al., 2014).

In the ever-changing working environment that is characterized by high teaching and research demands, it is a significant challenge for faculty members to perform well and make important contributions. Thus, knowledge about factors related to faculty performance are crucial for understanding how to support these processes. Regarding predictors of faculty performance, demographic, institutional, and social-environmental factors have been found to only explain limited variability in faculty behaviors, which emphasizes the consideration of personal aspects such as faculty members' motivations to understand differences in their performance at work (Harrison \& Kelly, 1996; Ponjuan et al., 2011; Stupnisky et al., 2015). This goes in line with the predictive utility of motivational variables for performance and well-being that has consistently been documented among students and K-12 teachers (Lazowski \& Hulleman, 2016; Richardson et al., 2014; Robbins et al., 2004; Tönjes \& Dickhäuser, 2009).

\subsection{Achievement Goals of Faculty for Teaching and Research}

Faculty motivation refers to the overall processes that give rise to initiating, sustaining, and regulating goal-directed behaviors. A prominent approach to describe and explain faculty motivation is the achievement goal approach (Dweck, 1986; Elliot \& Hulleman, 2017; Nicholls, 1984). This approach distinguishes different types of goals that individuals can pursue to different strengths in achievement contexts and for which different affective, cognitive, and behavioral consequences have been documented (Hulleman et al., 2010; Payne et al., 2007).
While individuals pursue multiple different goals at the same time, to different strengths, there is an ongoing debate regarding the number and content of the different types of goals that should be theoretically distinguished (e.g., Elliot \& McGregor, 2001; Elliot et al., 2011; Vansteenkiste et al., 2014). Fundamentally distinguished are mastery-based goals (focused on doing tasks correctly and on the development of competence) and performance-based goals (focused on one's performance relative to others and as perceived by others). Moreover, most researchers agree that goals can be characterized by an approach or an avoidance goal valence (i.e., whether desired end-states are sought to be approached, or undesired end-states are sought to be avoided; Murayama et al., 2011). Furthermore, researchers have suggested that a finer differentiation and a disentanglement, based on the content of masteryand performance-based goals, is necessary (Brophy, 2005; Elliot, 2005; Grant \& Dweck, 2003; Hulleman et al., 2010). Specifically, performance goals are distinguished (see Elliot, 1999, 2005; Hulleman et al., 2010; Lee \& Bong, 2016; Senko \& Dawson, 2017; Urdan \& Mestas, 2006) based on an appearance component (striving to be perceived as competent or not to be perceived as incompetent, irrespective of personal performance) and a normative component (striving to be more competent than others or not worse than others regarding actual performance). Mastery goals are distinguished (e.g., Elliot et al., 2011), according to whether the standard for evaluating one's own competence lies in the task ("task goals") or in one's intrapersonal development ("learning goals"). Lastly, two further types of goals have been proposed as they hold great relevance in the teaching and work context (see for example Butler, 2012; Butler \& Shibaz, 2008; King \& McInerney, 2014): work avoidance goals (striving to get through the day with little effort) and relational goals (striving to create close and caring relationships with relevant others, such as students in the teaching domain, or colleagues in the research domain).

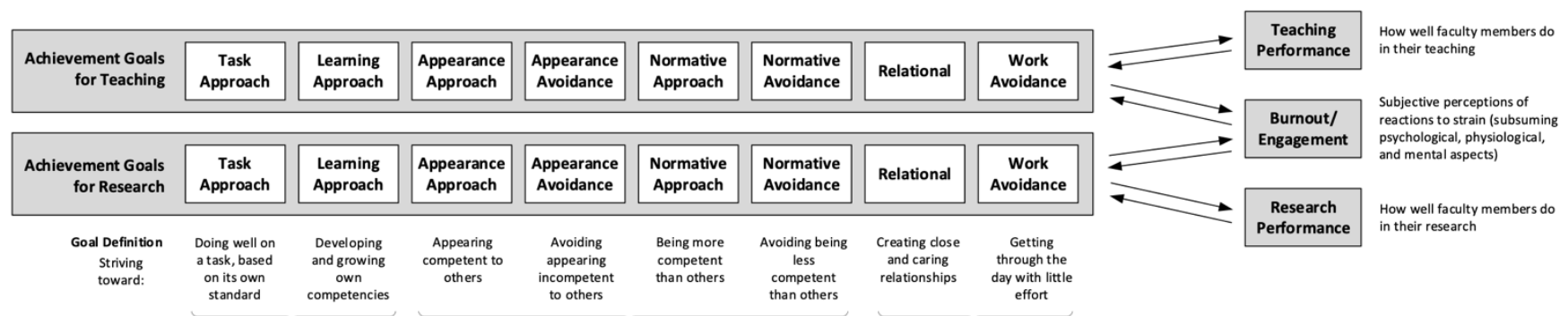

Figure 1. Overview model depicting the investigated types of goals and their definitions (based on Butler, 2012; Elliot, 2005; Elliot et al., 2011; Grant \& Dweck, 2003; Hulleman et al., 2010; see Daumiller et al., 2019) and the temporal associations with burnout 
Extending results from interview studies documenting that faculty members do indeed pursue these goals for teaching (Daumiller et. al., 2015) and for research (Daumiller \& Dresel, 2020a), Daumiller et al. (2019) proposed an integrative achievement goal framework (encompassing the above-described two facets of mastery goals and the two facets of performance goals with an approach and avoidance orientation, as well as relational and work avoidance goals as two additional types of goals) suitable for describing faculty motivation and studying the effects that different facets of goals may entail. Building on this, research has shown that these goals can be distinguished between teaching and research domains, with teaching goals sharing about half of their variance with research goals (Daumiller \& Dresel, 2020b) - which matches well to the correlations observed for students' achievement goals regarding different subjects (see Bong, 2001, 2004; Sparfeldt et al., 2015; Sparfeldt et al., 2007). This implies that different qualities of motivation exist for both domains - meaning that the respective goals can be pursued to different extents between both domains - and that university scholars' achievement goals need to be analyzed separately given that these domains represent rather distinct contexts with different tasks, and at the same time constitute the two central and most time-intensive aspects of university scholars' work (Marsh \& Hattie, 2002). While systematic differences can thus be expected between these two work domains and should be followed up on, it is worth mentioning that prior research has typically not found indications for meaningful differences in how faculty members' motivations are linked to other variables across different academic disciplines or across different types of institutions (see Authors, 2021; Hardré et al., 2011; Stupnisky et al., 2018).

Further, past research has provided indications that the different types of goals may indeed encompass different relations with other constructs (e.g., Daumiller et al., 2019; Daumiller \& Dresel, 2020a; Hein et al., 2019; Janke et al., 2019), and should therefore be studied on a fine-grained level. For burnout/engagement and performance, we have derived clear expectations regarding the relevance of these goals (summarized in Figure 1), which we outline in the next section. An exception to this is mastery-avoidance goals: While empirically separable from mastery-approach goals, past research on faculty motivation did not provide clear indications for these types of goals mattering for experiences and behaviors (see also Murayama et al., 2012), and also theoretically, we do not have a rationale for the rele- vance of mastery avoidance goals for burnout/engagement and performance. Therefore, we do not consider mastery avoidance goals in the present work.

\subsection{Linkages Between Achievement Goals and Burn- out/Engagement and Performance}

Achievement goals are posited to underlie differences in how individuals experience and interpret achievement situations (McGregor \& Elliot, 2002), such as teaching and research, which are coined by both personal development and learning as well as performance relative to and in front of others. As such, goals can be expected to influence the formation of professional stress. Specifically, the motivational systems spanned up by pursuing the different goals can be considered as resources or determinants of how individuals appraise stressors (Folkman et al., 1986). Achievement goals also orient individuals towards choosing different tasks and pursuing them with different levels of commitment (Hulleman et al., 2010), which is why they should also be related to teaching and research performance.

Specifically, as they focus on doing tasks well and developing own competencies, mastery approach goals should go along with perceiving (even stressful) achievement situations as positive and controllable, and therefore can be expected to be linked to reduced burnout levels. Moreover, given this focus, greater work engagement and dealing well with challenging situations are to be expected, and, in turn, mastery approach goals should additionally be positively linked with performance. Indeed, research on faculty has found mastery approach goals in teaching and research domains to be negatively related to burnout experiences and positively to aspects of subjective well-being as well as engagement (Daumiller et al., 2019; Daumiller \& Dresel, 2020a; Janke \& Dickhäuser, 2018; Rinas et al., 2020). This also matches well to research on school teachers that has documented that stronger mastery goals go along with fewer burnout experiences (e.g., Fasching et al., 2010; Retelsdorf et al., 2010; Tönjes \& Dickhäuser, 2009) as well as the use of coping strategies (Parker et al., 2012). Furthermore, mastery goals have been clearly positively associated with performance in different domains, including the work domain (Hulleman et al., 2010; Senko et al., 2011; van Yperen et al., 2014), and faculty teaching quality (Daumiller et al., 2021; Daumiller et al., 2019; however, the associations with student reports of teaching quality are sometimes mixed; Daumiller et al., 2021; Daumiller et al., 2016). 
Moreover, studies that investigated both task and learning goals in this population often found stronger and more consistent relations with performance outcomes for task instead of learning goals (e.g., Daumiller et al., 2019; Mascret et al., 2017), which could point to a different relevance of these two aspects for performance outcomes - at least in the teaching domain.

Performance approach goals combine a favorable orientation of seeking to approach the respective outcomes with a focus on performance that can be deemed unfavorable regarding burnout experiences. This combination therefore does not allow for clear theoretical expectations regarding their associations with burnout/engagement. Also empirically, past research has not reported significant associations for these goals with burnout/engagement or related constructs such as satisfaction (e.g., Daumiller \& Dresel, 2020a; Janssen $\&$ van Yperen, 2004; Nitsche et al., 2013; van Yperen \& Jansssen, 2002). However, regarding achievement, the orientation towards performance is adaptative for reaching the respective goal, as also indicated by research on students and athletes (Hulleman et al., 2010; Senko et al., 2011; van Yperen et al., 2014). It is worth noting that research on students points to differences in the functionality of normative and appearance aspects of performance goals (e.g., Hulleman et al., 2010). In the teaching domain, Daumiller, Janke et al. (2021), Daumiller, Rinas et al. (2021), Daumiller et al. (2019), Daumiller et al. (2022) reported a positive association between appearance (but not normative) approach goals and performance, which could be a function of teaching performance being strongly tied to how it is perceived by students (focus on appearance component). While performance goals have not yet been investigated with regard to performance in the research domain, it could be possible that normative goals matter more in this domain (similar to the clearly derived and frequently inherently normative comparisons underlying performance in school and academia).

For performance avoidance goals, associations with increased burnout levels and impaired performance can be expected, given that this type of motivation orients individuals towards perceiving achievement situations as threatening and being worried about failure. The linkages with impaired performance are empirically well-documented in diverse populations (Hulleman et al., 2010; Senko et al., 2011; van Yperen et al., 2014). Further, clearly positive associations have also been reported with burnout experiences (Daumiller, Rinas et al., 2021; Papaioannou \& Christodoulidis, 2007; Retelsdorf et al., 2010; Tönjes et al., 2008). To this end, it has been noted that especially normative strivings may be linked to the development of high burnout levels in teaching and research professions (Daumiller et al., 2019; Daumiller \& Dresel, 2020a; Friedman, 2000). However, considering the adverse relation between self-presentation strategies and well-being (Giacalone \& Promislo, 2014), appearance aspects may also be relevant.

Relational goals are generally still only little investigated. Regarding burnout levels, built-up relationships could serve as coping opportunities (e.g., discussing research problems with colleagues as a form of active, problem-oriented coping), however, the processes involved in caring about developing relationships could also be straining (e.g., being committed to facilitating strong relationships with students could be perceived as stressful when this goal is not achieved right away), yielding unclear expectations for this type of goal. Regarding teaching quality, relational goals have been posited to be adaptive, as a high teaching quality also requires a good relationship with students (Butler, 2012). Empirically, positive links with aspects of selfand student-reported teaching quality have been observed in higher education (Daumiller et al., 2021; Daumiller et al., 2019; Han et al., 2015; Yin et al., 2017). No prior studies have investigated the relevance of relational goals for research performance. However, given that research performance also depends on cooperating and working together with others, relational goals might also be facilitative for performance in this domain.

Finally, work avoidance goals should positively be related to burnout levels given that this motivational orientation is considered an adverse coping strategy over time and reduces the available resources required for dealing with work stress (Salmela-Aro et al., 2009). From an empirical perspective, work-avoidance goals have been positively associated with number of sick days used and burnout levels (Daumiller \& Dresel, 2020a; Retelsdorf et al., 2010; Fasching et al., 2010; Nitsche et al., 2013), as well as negative emotional experiences (Daumiller et al., 2019; Janke et al., 2019; Rinas et al., 2020). Similarly, as attaining high performance requires investing effort, work avoidance should be negatively linked to performance, as clearly indicated by studies involving teachers and faculty members (e.g., Daumiller et al., 2021; Daumiller, Janke et al., 2021; Daumiller, Rinas et al., 2021; Daumiller et al, 2016; Janke \& Dickhäuser, 2018).

These theoretical considerations and empirical findings allow for clear expectations as to how goals are related to burnout/engagement as well as teaching and research performance. As indicated above, however, 
also differences between the different facets of mastery and performance goals can be expected, pointing to the necessity of their consideration to better understand the modes of operations of these different motivational orientations. Furthermore, the effects of the achievement goals may differ between the domains (e.g., relevance of relational or appearance/normative goals). In particular, given that the research domain is frequently considered to be more relevant for faculty self-worth, overall burnout/engagement may be tied more strongly to research goals than to teaching goals. For a comprehensive understanding of the associations of faculty goals and burnout/engagement and performance, it is therefore necessary to consider both work domains. Finally, it also needs to be considered that most of the abovementioned research works were only cross-sectional, and while within these works goals were typically expected to affect burnout/engagement and performance, also reverse effects stand to reason and need to be considered, as we illustrate next.

\subsection{Temporal Dynamics: Goals as Concomitant, Causes, or Consequences?}

Achievement goal research has generally focused primarily on unidirectional effects of goals on outcomes such as professional stress, while reciprocal relationships have been neglected (cf. King \& McInerney, 2016). However, theoretical reasoning on the dynamic nature of goal pursuit (DeShon \& Gillespie, 2005) indicates that it is likely that goals and aspects such as burnout/engagement and performance can reciprocally influence each other across time (see also Marsh et al., 2005, on how achievement can influence motivational processes). For example, based on a sample of 471 faculty members who were surveyed regarding their achievement goals and burnout/engagement, Daumiller and Dresel (2020a) conducted cross-lagged panel analyses and found that only normative avoidance goals had a statistically significant influence on burnout/engagement after 6 months (but not the other goals), while burnout/engagement at the first measurement point was linked to subsequent task approach and learning approach goals (negatively) and work avoidance goals (positively). While the respective study is limited in that only one domain (research) and only one criterion (burnout/engagement but not performance) was considered in two measurement points, this does provide first empirical evidence regarding the existence of reverse effects regarding faculty goals. Indeed, it seems sensible that reducing resource-intensive goals, such as mastery goals, and increasing work avoidance goals, can serve to deal with high stress levels (Gmelch, 1993). Further, it theoretically also makes sense that high performance may give rise to differences in goal pursuit, such as increased performance goals in order to demonstrate one's achievements. Therefore, reverse or reciprocal effects can be considered as reasonable and need to be addressed for a thorough understanding of the role of goals for burnout/engagement and performance.

Considering the different patterns of temporal associations four different types of relations can be distinguished, which we illustrate with regard to burnout/engagement. Specifically, it could be the case that (A) goals influence the growth of burnout levels (e.g., pursuing strong normative avoidance goals could make achievement situations appear as subjectively more exhausting and stressful). However, the reverse direction also seems reasonable with (B) burnout levels affecting goal pursuit (e.g., when confronted with much stress at work, an individual might start to pursue strong workavoidance goals as a coping strategy or reduce mastery goals to save resources for dealing with work stressors). Lastly, it also possible that no causal relations between both constructs can be identified but that both goals and burnout levels are related in that $(\mathrm{C})$ their levels are associated with each other or that (D) they covary across time caused by unobserved third variables.

Considering these possible temporal relationships between goals and burnout/engagement and performance, is should be borne in mind that not all goals may be related in a similar way, but that differences could emerge between the different types of goals (such as normative avoidance goals affecting subsequent development of burnout levels, but work avoidance goals being a function of burnout levels) as well as the two domains. This necessitates comprehensive longitudinal analyses to elucidate the temporal dynamics between these constructs.

\subsection{Research Questions and Hypotheses}

The central aim of this study was to examine the temporal relationships between achievement goals and burnout/engagement as well as performance while considering teaching and research domains simultaneously. Based on theorizing into the different motivational systems spanned up by the different goals and prior research, we hypothesized that:

(1) Mastery and performance approach as well as relational goals are positively related to teaching and research performance; performance avoidance and 
Table 1

Descriptive Statistics of Achievement Goals, Burnout/Engagement, and Performance at the Four Measurement Points

\begin{tabular}{|c|c|c|c|c|c|c|c|c|c|c|c|c|c|c|c|c|c|c|c|c|c|}
\hline & \multicolumn{5}{|c|}{$\mathrm{T} 1$} & \multicolumn{5}{|c|}{$\mathrm{T} 2$} & \multicolumn{5}{|c|}{$\mathrm{T} 3$} & \multicolumn{5}{|c|}{$\mathrm{T} 4$} & \multirow[b]{2}{*}{ ICC } \\
\hline & $\omega$ & Range & $M$ & $S D$ & Skew & $\omega$ & Range & $M$ & $S D$ & Skew & $\omega$ & Range & $M$ & $S D$ & Skew & $\omega$ & Range & $M$ & $S D$ & Skew & \\
\hline \multicolumn{22}{|c|}{ Achievement goals for teaching } \\
\hline Task approach & .85 & $3.8-8.0$ & 7.29 & 0.78 & -1.32 & .85 & $2.0-8.0$ & 7.17 & 0.86 & -1.98 & .86 & $3.5-8.0$ & 7.08 & 0.82 & -1.12 & .88 & $2.0-8.0$ & 6.97 & 0.95 & -1.48 & .56 \\
\hline Learning approach & .89 & $2.0-8.0$ & 6.75 & 1.11 & -0.98 & .91 & $2.0-8.0$ & 6.68 & 1.14 & -1.05 & .91 & $1.8-8.0$ & 6.58 & 1.15 & -0.85 & .92 & $2.3-8.0$ & 6.49 & 1.20 & -0.95 & .64 \\
\hline Appearance approach & .89 & $1.0-8.0$ & 6.16 & 1.37 & -0.94 & .91 & $1.8-8.0$ & 6.01 & 1.38 & -0.93 & .91 & $1.0-8.0$ & 5.91 & 1.33 & -0.98 & .91 & $1.0-8.0$ & 5.85 & 1.36 & -0.96 & .65 \\
\hline Appearance avoidance & e.95 & $1.0-8.0$ & 6.31 & 1.70 & -1.30 & .95 & $1.0-8.0$ & 6.20 & 1.75 & -1.13 & .94 & $1.0-8.0$ & 6.15 & 1.69 & -1.01 & .95 & $1.0-8.0$ & 6.10 & 1.77 & -1.09 & .66 \\
\hline Normative approach & .95 & $1.0-8.0$ & 4.01 & 1.93 & 0.07 & .95 & $1.0-8.0$ & 4.09 & 1.86 & -0.01 & .96 & $1.0-8.0$ & 4.22 & 1.83 & -0.20 & .96 & $1.0-8.0$ & 4.18 & 1.87 & -0.11 & .70 \\
\hline Normative avoidance & .95 & $1.0-8.0$ & 5.68 & 1.94 & -0.77 & .96 & $1.0-8.0$ & 5.62 & 1.96 & -0.76 & .96 & $1.0-8.0$ & 5.57 & 1.94 & -0.68 & .96 & $1.0-8.0$ & 5.47 & 1.98 & -0.64 & .65 \\
\hline Relational & .75 & $1.0-8.0$ & 4.84 & 1.44 & -0.19 & .79 & $1.0-8.0$ & 4.71 & 1.51 & -0.16 & .84 & $1.0-8.0$ & 4.63 & 1.44 & -0.06 & .83 & $1.0-8.0$ & 4.58 & 1.54 & -0.12 & .67 \\
\hline Work avoidance & .93 & $1.0-8.0$ & 2.90 & 1.78 & 0.88 & .94 & $1.0-8.0$ & 2.87 & 1.82 & 0.91 & .95 & $1.0-8.0$ & 2.99 & 1.87 & 0.91 & .94 & $1.0-8.0$ & 3.09 & 1.82 & 0.82 & .70 \\
\hline \multicolumn{22}{|c|}{ Achievement goals for research } \\
\hline Task approach & .87 & $2.0-8.0$ & 7.25 & 0.85 & -1.66 & .87 & $2.8-8.0$ & 7.15 & 0.91 & -1.59 & .89 & $1.0-8.0$ & 7.02 & 1.03 & -1.72 & .88 & $2.5-8.0$ & 6.97 & 1.02 & -1.32 & .70 \\
\hline Learning approach & .88 & $3.5-8.0$ & 7.33 & 0.78 & -1.39 & .91 & $2.3-8.0$ & 7.16 & 0.92 & -1.49 & .93 & $1.0-8.0$ & 7.11 & 0.98 & -1.49 & .92 & $2.0-8.0$ & 7.05 & 1.00 & -1.38 & .61 \\
\hline Appearance approach & .92 & $1.0-8.0$ & 6.26 & 1.42 & -1.16 & .94 & $1.0-8.0$ & 6.11 & 1.42 & -0.99 & .94 & $1.0-8.0$ & 6.01 & 1.49 & -0.92 & .94 & $1.0-8.0$ & 6.04 & 1.50 & -1.08 & .69 \\
\hline Appearance avoidance & e.96 & $1.0-8.0$ & 6.35 & 1.71 & -1.30 & .96 & $1.0-8.0$ & 6.29 & 1.73 & -1.16 & .96 & $1.0-8.0$ & 6.29 & 1.71 & -1.14 & .96 & $1.0-8.0$ & 6.19 & 1.82 & -1.17 & .68 \\
\hline Normative approach & .95 & $1.0-8.0$ & 4.12 & 1.95 & 0.09 & .97 & $1.0-8.0$ & 4.16 & 1.95 & 0.04 & .97 & $1.0-8.0$ & 4.25 & 1.95 & -0.02 & .97 & $1.0-8.0$ & 4.20 & 1.95 & 0.00 & .71 \\
\hline Normative avoidance & .96 & $1.0-8.0$ & 5.65 & 1.96 & -0.72 & .97 & $1.0-8.0$ & 5.66 & 1.95 & -0.72 & .97 & $1.0-8.0$ & 5.56 & 1.95 & -0.66 & .96 & $1.0-8.0$ & 5.56 & 1.98 & -0.69 & .69 \\
\hline Relational & .85 & $1.0-8.0$ & 5.61 & 1.54 & -0.81 & .83 & $1.0-8.0$ & 5.50 & 1.49 & -0.65 & .96 & $1.0-8.0$ & 5.44 & 1.51 & -0.63 & .87 & $1.0-8.0$ & 5.39 & 1.55 & -0.64 & .61 \\
\hline Work avoidance & .92 & $1.0-8.0$ & 2.09 & 1.34 & 1.80 & .94 & $1.0-8.0$ & 2.17 & 1.46 & 1.65 & .95 & $1.0-8.0$ & 2.20 & 1.50 & 1.67 & .94 & $1.0-8.0$ & 2.37 & 1.55 & 1.48 & .60 \\
\hline \multicolumn{22}{|c|}{ Burnout/engagement and performance } \\
\hline Burnout levels & .90 & $1.1-7.0$ & 2.93 & 1.08 & 0.78 & .91 & $1.0-7.6$ & 2.99 & 1.14 & 0.87 & .92 & $1.0-7.3$ & 3.05 & 1.19 & 0.74 & .91 & $1.0-6.7$ & 3.02 & 1.16 & 0.62 & .73 \\
\hline Teaching performance & .81 & $3.8-8.0$ & 6.28 & 0.72 & -0.51 & .81 & $3.8-8.0$ & 6.34 & 0.69 & -0.36 & .84 & $3.3-7.9$ & 6.26 & 0.74 & -0.56 & .84 & $3.9-8.0$ & 6.29 & 0.73 & -0.67 & .65 \\
\hline Research performance & .92 & $0-96.5$ & 39.772 & 20.13 & -0.01 & .93 & $0-97.3$ & 38.81 & 20.74 & -0.05 & .94 & $0-95.1$ & 37.902 & 20.68 & 0.09 & .93 & $0-85.5$ & 38.272 & 20.38 & -0.07 & .83 \\
\hline
\end{tabular}

work avoidance goals are negatively related to performance.

Specifically, we expected these linkages for both the teaching and the research domains, but acknowledged that the relevance of these goals may vary between both domains (e.g., relational goals primarily mattering for teaching performance but less so for research performance).

(2) Mastery goals are negatively associated with burnout levels; performance avoidance and work avoidance goals are positively related to burnout levels. Regarding these burnout levels concerning the job as a whole, we expected that the goals from the research domain may be more strongly associated with them than the teaching goals, given the on average possibly weightier position of the research domain for selfworth of faculty members (Marsh \& Hattie, 2002).

Further, regarding mastery and performance goals, we presumed that the considered facets (task and learning goals; appearance and normative goals) may be differently related to burnout/engagement as well as teaching and research performance. Specifically, based on prior research, we expected that task goals may be more relevant for performance than learning goals; and appearance goals may be more relevant for teaching performance than normative goals.

The key innovation of our work is that we acknowledged that there are four different ways of how goals may be related to burnout/engagement as well as teaching and research performance over time. To elucidate the nature of the relationships between goals and burnout/engagement and performance, we were particularly interested in (A) how goal levels predict subsequent changes in burnout/engagement and performance, as well as (B) how burnout/engagement levels predict subsequent changes in goals. We considered that both temporal relations are reasonable and expected to find evidence for both. Further, we also considered how (C) the average levels of these constructs are related to each other over time, and (D) how changes in goals go along with changes in burnout/engagement and performance over time. We investigated all four types of relations for thorough insights into the temporal relations between these constructs.

\section{Method}

To answer our research questions, we conducted a longitudinal study that spanned over a total of two years. Relations between levels and temporal trends of 


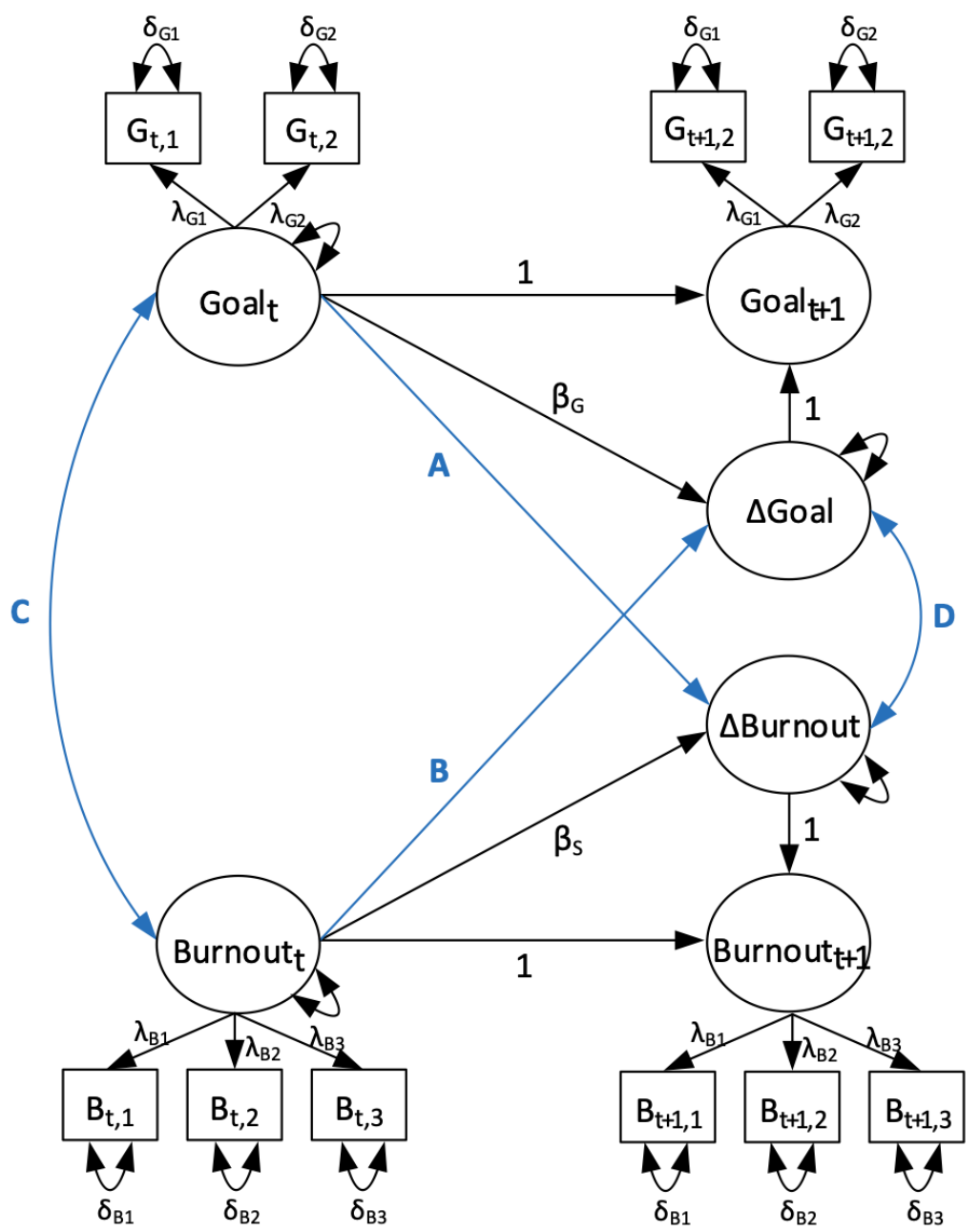

Figure 2. Illustration of a Bivariate Latent Change Score model. Highlighted in blue are the different types of temporal linkages that are reported in Table 1.

participants' goals, performance, and burnout at all four measurement points were analyzed through Latent Difference Score Modeling. We describe our sampling plan, all data exclusions (if any), all manipulations, and all measures in the study. Analysis code and research materials are available at https://osf.io/7u4ak). Data were analyzed using Mplus 8.1 (Muthén \& Muthén, 2018).

\subsection{Procedure and Sample}

We sent postcards to a random sample of faculty members from 85 universities across Germany to invite them to participate in our study. One-thousand-ninetysix faculty members returned the postcards. Their participation was encouraged by use of incentives: with each questionnaire, we included a small gift (such as a bag of tea), and participants who completed all questionnaires were offered a booklet with tips on how to be a professor. Of the 1,004 faculty members who agreed to participate in the study, 902 fulfilled the inclusion criterion and were invited to participate in the study by filling out a paper-and-pencil questionnaire four times every six months. The inclusion criterion required them to be active in both research and teaching. The sample was representative of scientific staff in German universities (with regard to gender and the percentage of professors; compared to data from the Statistisches Bundesamt, 2015). Our final sample consisted of those who participated in at least two measurement points, totaling 681 German faculty members from public universities. At the first measurement point, $51 \%$ reported being male, $42 \%$ female, and $7 \%$ did not disclose their gender; $67 \%$ were academic faculty members with $\mathrm{PhD}$, and $25.3 \%$ were full professors; their average age was $38.7(\mathrm{SD}=11.0)$ years; and they were active in the fields of biology (8\%) chemistry (8\%), economic sciences (7\%, English/American studies $(7 \%)$, German studies (10\%), mathematics (14\%), pharmaceutics $(2 \%)$, political sciences $(8 \%)$, romance 
studies $(7 \%)$, sports sciences $(10 \%)$, and further subjects $(4 \%)$. Of the 681 faculty members, 168 participated in two measurement points, 217 in three measurement points, and 296 in all four measurement points. The number of participants at T1, T2, T3, and T4 was $632,576,504$, and 459. Drop-out analyses did not provide indications that the amount of measurement points was systematically related to any of the assessed constructs (bivariate correlations with all assessed constructs: $|r| \leq .08$ with $\mathrm{p}>.06$ ).

\subsection{Measurements}

Through anonymous paper-and-pencil questionnaires that we linked using a code that was self-generated by the participants, we asked in each measurement point about achievement goals for teaching and for research, burnout/engagement levels, and self-reported teaching and research performance. The internal consistencies of all constructs were good at all measurement points (see McDonald's $\omega$ values reported in Table 1).

\subsubsection{Achievement Goals for Teaching and Research}

We used the faculty member achievement goal scale by Daumiller et al. (2019), distinguishing between task and learning approach as mastery-based goals, appearance and normative goals as performance-based goals (each with an approach and avoidance component), as well as work-avoidance and relational goals. Prior research confirmed parallel versions of this scale to measure achievement goals for teaching (Daumiller et al., 2019) and for research (Daumiller \& Dresel, 2020a). Following the item stem "In my current [teaching/research] activities, ...", we used four items each for task approach (e.g., "... I want to fulfill the different requirements very well"), learning approach (e.g., “... I want to constantly improve my competencies"), appearance approach (e.g., "... I want to be perceived as competent"), appearance avoidance (e.g., "... I want to avoid being perceived as incompetent"), normative approach (e.g., "... I want to be better than my colleagues”), normative avoidance (e.g., “... I don't want to be worse than my colleagues"), relational (e.g., “... it is important for me to achieve a personal connection with [students/my colleagues]"), and work avoidance goals (e.g., "... I want to have as little to do as possible") that were to be assessed on a Likert-type scale from 1 (do not agree at all) to 8 (agree completely). Confirmatory factor analyses (CFAs) attested factorial separability of the assessed goals (achievement goals for teaching: $\mathrm{CFI}=.98$, TLI $=.99$, RMSEA $=.05$,
SRMR = .04; achievement goals for research: $\mathrm{CFI}=$ .99 , TLI $=.99$, RMSEA $=.04$, SRMR $=.03$ ), and confirmed their measurement invariance across the four measurement points (deterioration in fit from configural to metric, and from metric to scalar model: $\triangle \mathrm{CFI} \leq$ $.01, \Delta \mathrm{RMSEA} \leq .01, \Delta \mathrm{SRMR} \leq .01){ }^{2}$

\subsubsection{Job Burnout/Engagement}

To measure participants' job burnout/engagement, we employed a validated German translation of the MBI for general professions (MBI-GS-D; Büssing \& Glaser, 1998) that has been slightly modified for the academic context in past research (Daumiller \& Dresel, 2020a). It entails (a) emotional exhaustion (e.g., "I feel emotionally exhausted by my work"; 6 items), (b) cynicism (e.g., "I just want to do my job and be left alone"; 5 items), and (c) reduced personal accomplishment (e.g., "I feel good when I have achieved something at work"; 5 reverse scored items that were subsequently inverted). We asked the participants to refer their answers to their current work at the university and to indicate on an 8-point Likert-type scale ranging from 1 (never) to 8 (very often) how often they experienced the presented aspects within the past 6 months. As we were interested in burnout/engagement as a whole instead of the underlying dimensions, we analyzed it on the overall scale level (following the recommendations by Brenninkmeijer \& van Yperen, 2003) by averaging the three facets to a uniform indicator of burnout/engagement (also justified by sufficiently large inter-correlations, $\rho=.41-.61$ ). CFAs confirmed this factorial structure (superordinate one-factor model with residual method factors for the three subfacets: CFI $=.99$, TLI $=.99, \mathrm{RMSEA}=.04, \mathrm{SRMR}=.03$ ) and measurement invariance over time (deterioration in fit from configural to metric, and from metric to scalar model $\Delta \mathrm{CFI} \leq$ $.01, \Delta \mathrm{RMSEA} \leq .01, \Delta \mathrm{SRMR} \leq .01)$.

\subsubsection{Teaching Performance}

To assess teaching quality, we used the validated self-report scale by Daumiller et al. (2019) that asks instructors for self-assessments regarding the aspects of teaching quality distinguished in the German translation of the SEEQ (Students' Evaluations of Educational Quality, the internationally most widely used instrument to assess higher education teaching quality; Marsh, 2007; Daumiller, Grassinger et al., 2021). With reference to all courses that they were teaching, participants rated how well they implemented the respective ten aspects of teaching quality on a Likert-type scale from 1 (very poor) to 8 (very well). The items corresponded to the respective teaching quality dimensions 
and entailed descriptions of their content in brackets, for example: "Breadth (extent to which you encourage your students to participate during your courses; such as contributing their own knowledge, asking questions, participating during discussions, etc.)". The validity of this scale for reflecting differences in overall teaching quality between different higher education teachers has been shown in past research (high correlation between faculty members' answers on this scale and students' bias- and unfairness-corrected evaluations of teaching quality: $\rho=.74$; Daumiller et al., 2022). CFAs confirmed the presumed one-factorial structure $(\mathrm{CFI}=.95$, $\mathrm{TLI}=.97, \mathrm{RMSEA}=.06, \mathrm{SRMR}=.05)$ and measurement invariance over time (deterioration in fit from configural to metric, and from metric to scalar model $\Delta \mathrm{CFI} \leq .01, \Delta \mathrm{RMSEA} \leq .01, \Delta \mathrm{SRMR} \leq .01)$.

\subsubsection{Research Performance}

We used the Short Multidisciplinary Research Performance Questionnaire (SRMPQ; Daumiller et al., 2019) that encompasses 11 quantitative and qualitative self-reported indicators of research performance. With regard to the last six months, participants rated how well they did regarding these aspects with regard to their fellow researchers with the same status and discipline (e.g., "Over the last six months, I published more than _ $\%$ of my fellow researchers with the same status and discipline"). Notably, this scale does not only focus on specific aspects of research performance, as would be the case with bibliometric data, but comprehensively considers research performance by quantitative and qualitative performance aspects from four areas (research quality, facilitation, transfer/exchange, and reputation). Building on objective (e.g., amount of publications retrieved from publication lists) and subjective (e.g., established self-assessment scales for external criteria) validation data, past research documented that this self-report scale provides a valid (correlation with validation measure: $r=.75$ ), well understandable and answerable, as well as economical approach for assessing research performance of individual researchers across different disciplines, especially for research studies such as the present investigation where personal correlates of research performance are investigated (Daumiller Siegel et al., 2019). CFAs confirmed the expected one-factorial structure $(\mathrm{CFI}=.91$, $\mathrm{TLI}=.92$, RMSEA $=.08$, SRMR $=.05)$ and measurement invariance over time (deterioration in fit from configural to metric, and from metric to scalar model $\Delta \mathrm{CFI} \leq .01, \Delta \mathrm{RMSEA} \leq .01, \Delta \mathrm{SRMR} \leq .01)$.

\subsection{Analyses}

To answer our research questions, we conducted Latent Change Score Modeling (LCS; Ferrer \& McArdle, 2010; McArdle, 2001) which is appropriate to test lagged and reciprocal effects associated with inter-individual differences in change. Essentially, this approach models a latent change variable representing gains or losses in the true score for each variable between two consecutive measurement occasions. This latent slope as well as the latent intercept can be used to test associations with growth parameters of other constructs. All models were based on lag-data containing information from one measurement point and the following measurement point, and the "type = complex" procedure was used in Mplus 8.1 for corrected estimates of the standard errors. All constructs were estimated as latent constructs based on item parcels as indicators (which is preferable to using all items as indicators as it reduces the amount of error in the estimations of complex models; Little et al., 2013). Following the item-to-construct method, we used two parcels for achievement goals and performance and three parcels for work stress (Little et al., 2002). Missing data (< $5.1 \%$ for each construct) was handled using the FullInformation Maximum Likelihood (FIML) estimation and the Expectation Maximization (EM) algorithm for all analyses (Peugh \& Enders, 2004).

Specifically, we estimated two sets of models. First, we conducted bivariate LCS models, in which we analyzed how each goal was related to burnout/engagement as well as research and teaching performance. In each model, we were interested in four types of associations: (A) how levels of achievement goals at time $t$ predicted subsequent change in burnout/engagement and performance from time $t$ to $t+1$, (B) how levels of burnout/engagement and performance at time $t$ predicted subsequent change in achievement goals from time $t$ to $t+1,(\mathrm{C})$ how levels of goals were related to levels of burnout/engagement and performance at time $t$, as well as (D) how changes in goals from $t$ to $t+1$ were related to changes in burnout/engagement and performance from $t$ to $t+1$ (see Figure 2 for an example).

Second, we estimated four multivariate LCS models (one model for each dependent variable and all achievement goals from the teaching or the research domain). In each multivariate model, we simultaneously considered all achievement goals from the respective domain that were found to be significantly related to burnout/engagement or performance in the bivariate models in that at least one of the four associations outlined above was statistically significant (see Figure S1 in the Supplemental Material). 
Table 2

Results of Multivariate Latent Change Score Models on the Associations Between Achievement Goals, Work Stress, and

Performance in Teaching and Research

\begin{tabular}{|c|c|c|c|c|}
\hline & \multicolumn{2}{|c|}{ Teaching domain } & \multicolumn{2}{|c|}{ Research domain } \\
\hline & $\begin{array}{l}\text { Model 1: } \\
\text { Burnout/ } \\
\text { engagement }\end{array}$ & $\begin{array}{c}\text { Model 2: } \\
\text { Teaching } \\
\text { performance }\end{array}$ & $\begin{array}{l}\text { Model 3: } \\
\text { Burnout/ } \\
\text { engagement }\end{array}$ & $\begin{array}{l}\text { Model 4: } \\
\text { Research } \\
\text { performance }\end{array}$ \\
\hline \multicolumn{5}{|c|}{ A. Effect of goals (at time $t$ ) on subsequent burnout/engagement and performance change $(t \rightarrow t+1)$} \\
\hline Task approach & $.06(.05)$ & $.10 *(.05)$ & $.05(.05)$ & $.08 *(.04)$ \\
\hline Learning approach & $.01(.04)$ & $.01(.04)$ & $-.03(.05)$ & $-.06(.04)$ \\
\hline Appearance approach & $-.06(.05)$ & $.13 * *(.05)$ & - & $-.01(.04)$ \\
\hline Appearance avoidance & $.01(.05)$ & $-.06^{*}(.04)$ & - & - \\
\hline Normative approach & $.01(.04)$ & - & $-.08 *(.03)$ & $.11^{* *}(.04)$ \\
\hline Normative avoidance & $-.02(.05)$ & - & $.09 *(.04)$ & $-.11 * *(.04)$ \\
\hline Relational & - & $-.02(.04)$ & - & - \\
\hline Work-avoidance & $.01(.04)$ & $.01(.04)$ & $.05 *(.04)$ & $-.05 *(.03)$ \\
\hline \multicolumn{5}{|c|}{ B. Effect of burnout/engagement and performance (at time $t$ ) on subsequent goal change $(t \rightarrow t+1)$} \\
\hline Task approach & $-.11^{* *}(.04)$ & $.20 * * *(.04)$ & $-.08 *(.03)$ & $.12 * * *(.03)$ \\
\hline Learning approach & $-.04(.03)$ & $.10 * * *(.02)$ & $-.07 *(.03)$ & $.12 * * *(.03)$ \\
\hline Appearance approach & $.04(.03)$ & $.04(.03)$ & - & $.14 * * *(.03)$ \\
\hline Appearance avoidance & $.05(.03)$ & $.04(.03)$ & - & - \\
\hline Normative approach & $.05(.03)$ & - & $-.01(.03)$ & $.12 * * *(.03)$ \\
\hline Normative avoidance & $.05(.03)$ & - & $.03(.03)$ & $.06 *(.03)$ \\
\hline Relational & - & $.03(.03)$ & - & - \\
\hline Work-avoidance & $.14 * * *(.03)$ & $-.11 * *(.04)$ & $.14 * * *(.03)$ & $-.08 * *(.03)$ \\
\hline \multicolumn{5}{|c|}{ C. Correlation between goals (at time $t$ ) and burnout/engagement and performance (at time $t$ ) } \\
\hline Task approach & $-.21 * * *(.04)$ & $.44^{* * *}(.04)$ & $-.25 * * *(.04)$ & $.25^{* * *}(.03)$ \\
\hline Learning approach & $-.13 * * *(.04)$ & $.30 * * *(.04)$ & $-.26 * * *(.04)$ & $.19^{* * *}(.04)$ \\
\hline Appearance approach & $.07 *(.04)$ & $.18 * * *(.04)$ & - & $.22 * * *(.04)$ \\
\hline Appearance avoidance & $.10^{* *}(.04)$ & $.06(.04)$ & - & - \\
\hline Normative approach & $.11^{* *}(.04)$ & - & $.07(.04)$ & $.20 * * *(.04)$ \\
\hline Normative avoidance & $.07 *(.04)$ & - & $.05(.04)$ & $.10 * *(.04)$ \\
\hline Relational & - & $.24 * * *(.03)$ & - & - \\
\hline Work-avoidance & $.36 * * *(.03)$ & $-.30 * * *(.04)$ & $.40 * * *(.03)$ & $-.20 * * *(.03)$ \\
\hline \multicolumn{5}{|c|}{ D. Correlation between goal change $(t \rightarrow t+1)$ and burnout/engagement and performance change $(t \rightarrow t+1)$} \\
\hline Task approach & $-.08 * *(.04)$ & $.18 * * *(.05)$ & $-.18^{* *}(.05)$ & $.10 * *(.03)$ \\
\hline Learning approach & $-.08 * *(.04)$ & $.15 * *(.05)$ & $-.20 * * *(.05)$ & $.10 *(.04)$ \\
\hline Appearance approach & $.06(.04)$ & $.07(.04)$ & - & $.09 *(.04)$ \\
\hline Appearance avoidance & $.01(.04)$ & $.09(.04)$ & - & - \\
\hline Normative approach & $.01(.04)$ & 一 & $.05(.04)$ & $.05(.04)$ \\
\hline Normative avoidance & $.03(.04)$ & - & $-.03(.04)$ & $.08(.04)$ \\
\hline Relational & - & $.19^{* * *}(.05)$ & - & - \\
\hline Work-avoidance & $.23^{* * *}(.03)$ & $-.11 *(.05)$ & $.21^{* * *}(.05)$ & $-.04(.04)$ \\
\hline
\end{tabular}

Note. Presented are standardized coefficients (with standard errors in brackets). Each model includes those goals that were statistically significantly related to stress or performance in prior bivariate latent change score models (see Figure 2 and Table S2). Not included goals are denoted with "-.". All constructs are modeled as latent factors based on item parcels. Correlations between achievement goals at time $t$ and correlations between changes of goals were included but are not presented for clarity. Likewise, effects from one variable at time $t$ on subsequent change in the same variable are not shown for clarity. Effects from goals at time $t$ on subsequent change in other goals were not modeled. All four models had a good fit to the data $\left(\chi^{2} \leq 867.3\right.$, $\mathrm{CFI} \geq .978, \mathrm{TLI} \geq .973, \mathrm{SRMR} \leq .042, \mathrm{RMSEA} \leq .031) .{ }^{*} p<.05,{ }^{* *} p<.01,{ }^{* * *} p<.001$. 


\section{Results}

Descriptively, our results pointed to similar mean levels (based on mean composites of their items) that have been reported in past research on faculty achievement goals for teaching and research (see Table 1). In particular, there were small mean level differences in goal pursuit between both domains in that in the teaching domain, stronger work avoidance goals and weaker learning goals were pursued compared to the research domain (see Daumiller \& Dresel, 2020a). Further, our results documented moderate temporal stabilities of the goals (ICC $=.56-.71)$, while the assessments of burnout/engagement and performance were descriptively slightly more stable $(\mathrm{ICC}=.65-.83)$. Further, there were moderate associations between achievement goals for teaching and achievement goals for research $(\mathrm{r}=.33-.80)$ that affirm the specificity of goal pursuit and the necessity of separately considering achievement goals for the teaching and the research domain (descriptively, these results replicate the findings by Daumiller and Dresel, 2020, with mastery approach goals being slightly more specific, and performance goals being more global regarding these two domains). Finally, it is worth noting that teaching and research performance were positively correlated $(\mathrm{r}=.25$; see Table $\mathrm{S} 1$ ), and burnout levels were negatively related to performance in both domains $(r=-.29, r=-.32)$ - with all three coefficients being rather small, which speaks to the appropriateness of analyzing their relations with the achievement goals in separate analyses.

The bivariate LCS models provided insights into how each goal was associated with teaching and research performance as well as burnout/engagement (see Table S2 in the Supplemental Materials). All goals from one domain that were significantly related to performance as well as burnout/engagement were then included in the multivariate LCS models to comprehensively analyze their relations (see Table 2, and Figure 3 for a visualization of the significant results). The results of the multivariate LCS modeling were overall very similar to the results of the bivariate LCM models, which affirms the robustness of these analyses.

For burnout/engagement and achievement goals for teaching (Model 1), we found that, with the exception of relational goals, all types of achievement goals were cross-sectionally related to the burnout levels as expected (C), while increases in burnout levels went along with decreases in task and learning approach goals and increases in work avoidance goals (D). Notably, we did not find indications for teaching goals to affect subsequent changes in burnout levels (A), however, higher burnout levels were related to a subsequent decrease in task-approach goals and an increase in work avoidance goals in the teaching domain (B).

Regarding the interrelations between achievement goals for research and burnout/engagement (Model 3), we found similar correlations between the intercepts and slopes of mastery approach and work avoidance goals as in the teaching domain. Levels and changes in task and learning approach goals were negatively related to levels and changes in burnout levels; while positive correlations emerged for work avoidance goals (C and $\mathrm{D})$. Also, comparable to the teaching domain, we observed that an increase in burnout levels was associated with a subsequent deterioration of both task and learning approach goals as well as an increase in work avoidance goals (B). Opposed to the teaching goals, however, we found that research goals mattered for the subsequent development of burnout/engagement in that normative approach goals negatively and normative avoidance as well as work avoidance goals positively predicted subsequent change in burnout levels (A).

Regarding teaching performance and achievement goals for teaching (Model 2), we found that levels and changes in task and learning approach goals as well as relational goals were positively related to levels and changes in teaching performance, while work avoidance goals were negatively related (C and D). Most importantly, our results indicated that task and appearance approach goals positively predicted subsequent changes in teaching performance, while appearance avoidance goals constituted a negative performance predictor (A). We also found evidence for reciprocal effects: Teaching performance positively predicted subsequent change in task and learning approach goals, and negatively predicted the development of work avoidance goals (B).

Finally, for research performance and achievement goals for research (Model 4), we observed similar effects for task and learning approach goals. In comparison to the teaching domain, however, work avoidance goals also emerged as a negative predictor of subsequent change in research performance (A). Also, instead of appearance goals, normative approach and avoidance goals predicted subsequent change in research performance (A). Finally, we observed that research performance positively predicted subsequent changes of appearance approach as well as normative approach and normative avoidance goals (B). 


\section{Discussion}

Faculty members' teaching and research are crucial to society and form a valuable research object to elucidate the role of goals for how one feels and performs in professional settings and how different domains can matter for that. Based on the notion that motivation is a central aspect for faculty members' experiences and performance, we investigated the role of achievement goals for two central constructs, burnout/engagement as well as performance in teaching and research. While past research has mostly focused on the teaching or the research domain, we investigated both domains simultaneously for a comprehensive understanding of these processes. Predominantly, we sought to elucidate the temporal directions of these linkages. We consider this a central contribution of the present work that should also be relevant for motivation research in general, as research typically presumes and investigates effects from goals on experiences and behaviors, while reverse or reciprocal effects are also reasonable yet seldom considered (cf. King \& McInerney, 2016). Strengths of our work include the large, representative sample that included assessments across two years, the use of validated scales to measure teaching and research performance, and the differentiated and parallel assessments of achievement goals in both domains that allowed for detailed insights into differences in their functioning. Using a Latent Difference Score approach, we found evidence for differentiated effects from goals on subsequent development of burnout/engagement and performance as well as reverse and reciprocal effects from these two core variables on subsequent changes in goals, which highlights the relevance of different types of achievement goals for burnout/engagement and performance of faculty and sheds light on their complex temporal dynamics that also include reverse effects and loops.

\subsection{Different Goals for Teaching and Research, and Over Time?}

Fundamentally, our analyses confirmed basic theoretical assumptions of achievement goals regarding their domain specificity and temporal stability. Corroborating past research and theorizing into attributes of goal pursuit (e.g., Bürger \& Schmitt, 2017; Praetorius et al., 2014; Sparfeldt et al., 2015), we found that variability in achievement goal pursuit contains person stable fractions, but that achievement goal pursuit also changes over time and differs between teaching and research domains. With regard to the latter, our results clearly replicated the findings by Daumiller and Dresel (2020b), thus emphasizing the necessity of jointly considering faculty motivations for both teaching and research, and not only as an overall domain-unspecific construct. Our findings also extend previous insights into the temporal stability of achievement goals (e.g., Praetorius et al., 2014; Senko et al., 2011), particularly with regard to faculty motivation (Janke \& Dickhäuser, 2018), by showing that also across distances of half a year, achievement goals contain around half temporally stable and half temporally variable fractions. The notion that goals are subject to change is a thereby a necessary foundation, not only for practical applications directed at supporting goal striving processes and our theoretical understanding of human goal pursuit, butpaired with only slightly smaller variability of burnout/engagement experiences and teaching and research performance - also for our main analyses, in which we illuminated the temporal mechanisms between levels and changes of achievement goals, burnout/engagement, and performance.

\subsection{How Are Goals Related to Burnout/Engagement Over Time?}

A main take-away from our results is that primarily achievement goals in the research domain seem to matter for the subsequent development of burnout/engagement levels. This may lie in the fact that, compared to teaching, research tasks are often closer to self-worth and career progress: While teaching is considered an integral element of academic work, faculty members often assign greater importance to research in that it is considered central to prestige, career development, and the allocation of resources (Esdar et al., 2011; Marsh \& Hattie, 2002; Smeby, 1998). Thus, well-being in the academic profession may be more strongly affected by research goals than teaching goals. An interesting follow up question linked to this may be whether faculty members' construe their well-being primarily with regard to their research experiences (and by extension, their research motivations may be more relevant thereto), or whether in the research domain, one's goals elicit differences in experiences to a greater extent than in the teaching domain - for example, because experiences in the research area are more directly a consequence of what one is doing; while in the teaching domain, multiple other factors, such as what students do, are decisive. To answer this question, we may consider research works that investigate more proximal experiences in both domains, such as emotions experienced 
in teaching and research. Finding stronger goal-emotion linkages in the research than in the teaching domain would indicate that our findings of differential relevance of goals in teaching and research domains for development of burnout/engagement may not solely be a function of how faculty construe their burnout experiences, but also of goals more or less strongly mattering for experiences of faculty in these two domains. We consider it a worthwhile and exciting direction for future research to distill the psychological mechanisms underlying these processes (e.g., by identifying the specific mechanisms underlying these relations, such as interpretation and coping with stressors). Doing so, it should be noted that our sample was based on German faculty members who were active in both research and teaching, while especially on an international level there are also faculty positions in which teaching is the primary or sole responsibility (Hüther \& Krücken, 2018). Accordingly, further investigations into how processes in the teaching and the research domain relate to burnout experiences in faculty would likely also profit from explicitly considering relevant moderating factors, such as the amount of expected time for teaching and research and their differential relevance for one's career.

With regard to which research goals affected subsequent development of burnout/engagement, we found that especially normative as well as work avoidance goals mattered. Given the high importance assigned to the research domain by faculty members, it appears sensible that reluctance to spend a lot of time and effort on research-related tasks (i.e., having strong workavoidance goals) facilitates the development of burnout experiences. At the same time, our findings on normative performance goals aligned well with the competitive nature of higher education systems, where particularly in the research domain, there is often high competition concerning job positions, research ideas, funding, etc. (Shin \& Jung, 2014). Thus, not caring about this competition by having weak normative approach goals may create a discrepancy between how one wants to orient their work and how the context requires it to be oriented, leading to impaired well-being over time. At the same time, being too worried about one's research performance relative to others (i.e., having strong normative avoidance goals) may be equally maladaptive in terms of stress experiences and worrying. We consider it an interesting perspective to follow up on these findings by also considering higher education systems in future research that are less competitive (Shin \& Jung, 2014) as well as individuals' perceptions of performance structures of their context to better understand when performance goals may be especially harmful for faculty well-being.

Conversely, our results also indicated that high burnout levels also impacted achievement goal pursuit in both domains in that task and learning goals were reduced and work avoidance goals were pursued more strongly. Given that mastery goals can be considered as more resource-intensive and work avoidance goals can serve to conserve resources, faculty members might construe this as a sensible coping strategy to deal with stress (see Hershcovis et al., 2018). The findings on the differences between the teaching and research domain illustrate that opposed to goals for research, burnout/engagement may rather form a predictor than a con-



Figure 3. Visualization of the linkages from goals on subsequent development of burnout/engagement and performance as well as the effects from burnout/engagement and performance on subsequent development of goals in the teaching and research domain. Presented are the significant linkages from our main analyses. Arrows with “+” indicate positive effects, arrows with "_” indicate negative effects. 
sequence of goals for teaching. We consider it a particularly worthwhile research direction to follow up on this finding by including measures to illuminate the respective processes. Specifically, considering relevant stressors from both domains and the coping strategies used to deal with them could serve to more fully understand the relevance of contextual features for how goals from different professional domains are related to wellbeing. Taken together, the findings on burnout/engagement show that both teaching and research motivations matter for a comprehensive understanding of how goals and well-being of faculty are linked and that a focus on a single domain (or university work as a whole) may be short-sighted.

\subsection{How Are Goals Related to Performance Over Time?}

Another key finding pertains to the associations with teaching and research performance. We found that in both domains, mastery goals were similarly positively related to performance; while between both domains, performance goals exhibited unique links and differed with regard to reciprocal relations with performance.

That task goals mattered more strongly for subsequent development of performance than learning goals matches with the idea that - especially in contexts where one's main tasks do not automatically equate to learning (as opposed to students, where the main task is usually defined by learning and improving own competences; for which differences between task and learning goals may be less clear) - task goals may be more relevant for performance than learning goals. This also aligns well with goal-setting theory (Locke \& Latham, 1990), as task goals may be more narrowly defined and thus superior to learning goals in terms of their specificity and difficulty. Here, we expanded past findings on task goals being more relevant for teaching quality and teaching practices (Daumiller et al., 2021, 2019; Mascret et al., 2017) to the research domain. Given the fairly consistent results between both domains, this may be interpreted as evidence that these findings can also be generalized to other occupational achievement contexts where (unlike students in schools) the main tasks do not primarily equate to learning. Compared to other types of job performance, one may argue especially well for research that this profession should ideally be driven through an innate desire to learn new things and to expand one's horizons. Nevertheless, specific aspects that are considered highly relevant components of research performance (such as amount of publications and acquired third-party funding) may in fact be hindered by a too strong inner desire to learn. Such aims could lead to losing track of the larger picture and the required output, potentially counteracting the positive effects that learning goals have for performance. That focusing on task goals may indeed be very sensible was also reflected in the effects from higher performance on subsequent increases in mastery goals that created a self-enforcing loop for task goals. This matches with first findings on performance eliciting subsequent changes in mastery goal pursuit by King and McInerney (2016) and aligns with the idea that low performance can lead to seeing oneself in a lower position relative to one's reference group and can thus lead to decreased engagement and mastery goal pursuit (as reflected in social comparison theory by Festinger, 1954, the frame of reference hypothesis by Marsh et al., 1986, and the inherent need to preserve ones self-worth as proposed by Covington, 2009).

Besides this, the results of performance goals matched well to the established positive linkages with performance for performance approach goals, and the negative linkages for performance avoidance goals (e.g., Hulleman et al., 2010; Senko et al., 2011; van Yperen et al., 2014), however, we found evidence for differential effects between both domains in that appearance goals were predictive of changes in teaching performance, and normative goals were associated with subsequent changes in research performance. This might be a function of inherent differences between conducting teaching and research, with teaching performance being primarily a function of how it is perceived by students (especially in contexts where teaching performance is typically evaluated through student assessments of teaching quality; Marsh, 2007) and research being more strongly normative-based and coined by high competition. In such a context, primarily hard "facts" often matter (such as third-party funding or the amount of publications). This extends prior research on appearance and normative aspects representing different aspects of performance goals that can entail different effects (Brophy, 2005; Elliot, 2005; Grant \& Dweck, 2003; Hulleman et al., 2010; see Daumiller et al, 2019). Our findings imply that, depending on the surrounding contexts and the affordances of performance, these two orientations may be differently relevant for performance through the distinct motivational systems that they span up. This does not only apply to performance approach goals (for which more inconsistent results are typically found) but also for performance avoidance goals. Clearly distinguishing performance goals between appearance and normative facets 
and acknowledging relevant context factors underlying how performance is construed, can thus be emphasized as an important implication for future research on the effects of performance goals.

Finally, regarding the two further, less investigated types of goals, we found clear indications for the relevance of work-avoidance goals that were more detrimental in the research than in the teaching domain. This is in line with prior findings on faculty members (Daumiller et al., 2021, Daumiller et al., 2019) and indicates that for teaching, it might be easier to get by with saving resources (e.g., by having students hold presentations; using the same lecture concept repeatedly) than regarding research. Conversely, we did not find any indications for the relevance of relational goals. This may not be surprising for the research domain, for which we had no clear expectations, but for teaching, relational goals are typically considered as an important foundation for high quality teaching processes (Butler, 2012; Butler \& Shibaz, 2014). This might especially be the case for teaching in primary and secondary education, but could be less clear in higher education, where sometimes also negative results are found for relational goals (Daumiller et al., 2021). To better understand the relevance of relational goals in higher education, we thus consider it necessary to consider moderators, such as types of classes taught (e.g., lecture versus seminar) or how often one sees and is able to interact with students.

\subsection{Limitations and Practical Implications}

When interpreting our findings, four important limitations should be borne in mind. First, while our survey design was longitudinal and our analyses modelled latent change, which is very appropriate for examining temporal relationships between the investigated variables, this does not equate to interpreting these findings as "causal" relationships. As many of the considered variables cannot be manipulated due to practical and ethical reasons, longitudinal research as in our work may indeed provide the best inferences about causal relationships beyond other research designs such as experiments, but to gain more confidence regarding causal relations, it is necessary to replicate these findings while also considering further alternative causal factors.

Second, while self-reports are ideal for measuring cognitive constructs such as goals, and we used validated scales to assess performance that aligns well with non-self-reported data, burnout/engagement levels were also assessed through self-reports based on the
MBI. While this focuses well on subjective feelings of stress and strain, future research would profit from supplementing this with more objective data, such as psychosomatic complaints or number of sick days. Relatedly, it is worth noting that these self-reported levels of burnout/engagement most likely underestimate the actual prevalence of stress in faculty members, as those who feel highly stressed would probably have not invested the extra time and strain of participating in this study.

Third, while we used measures to assess teaching and research performance that have been confirmed and validated in past research, it should be borne in mind that they were not symmetrical: The teaching performance scale focused on product and process aspects of teaching quality and used a Likert-type scale reflecting how well participants rated having fulfilled these aspects, while the research performance scale focused on one's research outcomes with regard to fellow researchers as a referent group. The different scales/referent groups do not allow for a comparison of teaching and research performance of individual faculty members. This is, however, not relevant for the present study given that we were primarily interested in modelling interindividual differences in performance in both domains - and relating these interindividual differences and their changes over time to interindividual differences in achievement goals and their changes over time. The slightly different emphases on process and product features of the respective performance, however, should be considered when interpreting the results on the goal-performance linkages. A relevant finding to this end was that, compared to the teaching domain, in the research domain performance affected the subsequent development of performance and workavoidance goals more strongly. In part, this result could also be a function of the research performance measure focusing more strongly on perceived outcomes of the performance in this domain, while process aspects were more strongly considered when evaluating one's teaching quality. This means that performance outputs might be more informative for goal-setting processes than process aspects. Future research on this topic could explicitly follow up on this perspective by measuring professional behaviors as well as performance outputs in both domains to more fully disentangle the respective processes.

Fourth, due to our study being fully anonymous, we have no information on the different types of institutes that the faculty members were from. While we were primarily interested in the longitudinal mechanisms between rather personal aspects, for research on more 
context-bound constructs-such as perceived support or need satisfaction and how these matter for the interpretation of stressors and goal-setting processes-it might be especially helpful to control for and follow up on such contextual features. Specifically, considering to which extent participants' experiences and behaviors are attributable to differences between labs, departments, or institutions can be especially helpful in determining which levels might be most relevant for supporting faculty members. Relatedly, considering contextual features, such as institutional emphases of teaching, research, support constructs such as balance, expectations, and collegiality (see Stupnisky et al., 2017) also appears warranted to follow up on our findings and examine how such aspects can support or hinder the relationships identified in the present work. Doing so, it might also be helpful to specifically consider traditionally underrepresented or disadvantaged groups of faculty members to better understand how different surrounding contextual features and intersectional identities based on, for instance, gender, race, or disability, can interact and give rise to possibly unique motivational dynamics (see Wigfield \& Koenka, 2020). After all, we know that different groups of faculty members can differ considerably in their experiences within the academy (see also Stupnsiky et al., 2015). While the general mechanisms linking goal pursuit to well-being and performance in faculty members (that we were interested in in the present study) should apply to the different groups of faculty members3, we consider it a highly relevant perspective for future research to explicitly focus on the individuality of faculty to better portray and understand their subjective reality.

Although more research is needed to understand how achievement goals affect well-being and performance in detail and how these processes can be supported, some preliminary practical implications can already be drawn: focusing on the goals in the research domain (instead of the teaching domain) may be an especially worthwhile direction to support faculty wellbeing. Here, scholars might be especially supported in dealing with high work load by other means instead of pursuing work-avoidance goals (e.g., prioritizing, using different resources) and dealing with competition in a healthy manner (e.g., construing it as healthy competition instead of worries about being outperformed). Further, with regard to performance, practical initiatives should possibly focus mainly on task goals. These aspects may be facilitated through directly addressing goal pursuit (e.g., in professional development courses, where the relevance of different goals can be discussed, and faculty can learn strategies to monitor and change their goal pursuit) or indirectly through supporting these goal striving processes by an arrangement of contextual features such as the goal structures and emphases within the department (Dickhäuser et al., 2021; Lüftenegger et al., 2014).

\subsection{Conclusion}

We analyzed the temporal dynamics between faculty members' achievement goals and two key aspects of their work: burnout/engagement and performance in teaching and research. Through Latent Change modeling and simultaneously considering teaching and research domains, we found that differences in achievement goals do not only give rise to subsequent changes in these variables, but also found strong evidence for reverse and reciprocal effects, thus drawing a more complex picture of motivational dynamics than unidirectional effects. Further, we illuminated the necessity of considering the surrounding context as well as different facets of goals, as these effects partly diverged between the teaching and research domain in that primarily research goals mattered for development of burnout experiences, while appearance and normative facets of performance goals mattered differently for teaching and research performance. Following up on this can be considered an important avenue to more fully understand the temporal dynamics of achievement goal pursuit and to adequately support faculty in feeling and performing well.

\section{References}

Barkhuizen, N., \& Rothmann, S. (2008). Occupational stress of academic staff in South African higher education institutions. South African Journal of Psychology, 38(2), 321-336. https://doi.org/10.1177/008124630803800205

Blix, A. G., Cruise, R. J., Mitchell, B. M., \& Blix, G. G. (1994). Occupational stress among university teachers. Educational Research, 36(2), 157-169. https://doi.org/10.1080/0013188940360205

Bong, M. (2001). Between-and within-domain relations of academic motivation among middle and high school students. Journal of Educational Psychology, 93(1), 23-34. https://doi.org/10.1037//0022-0663.93.1.23

Bong, M. (2004). Academic motivation in self-efficacy, task value, achievement goal orientations, and attributional beliefs. The Journal of Educational Research, 97(6), 287-298. https://doi.org/10.3200/joer.97.6.287-298

BrckaLorenz, A., Ribera, T., Kinzie, J., \& Cole, E. R. (2012). Examining effective faculty practice. To Improve The Academy, 31(1), 148-159. https://doi.org/10.1002/j.23344822.2012.tb00679.x

Brenninkmeijer, V. \& van Yperen, N. (2003). How to conduct research on burnout. Occupational and Environmental Medicine, 
60(Suppl. I), 16-20.

https://doi.org/10.1136/oem.60.suppl_1.i16

Brophy, J. (2005). Goal theorists should move on from performance goals. Educational Psychologist, 40(3), 167-176. https://doi.org/10.1207/s15326985ep4003_3

Bürger, K., \& Schmitt, M. (2017). Students' multiple state goals as a function of appraisals, trait goals, and their interactions. Contemporary Educational Psychology, 51, 464-481. https://doi.org/10.1016/j.cedpsych.2017.09.006

Büssing, A. \& Glaser, J. (1998). Managerial stress und burnout. A collaborative international study (CISMS). http://www.psy.wi.tum.de/LS-Berichte/Bericht-44.pdf

Butler, R. (2012). Striving to connect. Journal of Educational Psychology, 104(3), 726-742. https://doi.org/10.1037/a0028613

Butler, R., \& Shibaz, L. (2014). Striving to connect and striving to learn. International Journal of Educational Research, 65, 4153. https://doi.org/10.1016/j.ijer.2013.09.006

Butler, R., and Shibaz, L. (2008). Achievement goals for teaching as predictors of students'

perceptions of instructional practices and students' help seeking and cheating. Learning and Instruction, 18(5), 453-467. https://doi.org/ 10.1016/j.learninstruc.2008.06.004

Catano, V., Francis, L., Haines, T., Kirpalani, H., Shannon, H., Stringer, B., Lozanzki, B., (2010). Occupational stress in Canadian universities. International Journal of Stress Management, 17(3), 232-258. https://doi.org/10.1037/a0018582

Covington, M. (2009). Self-Worth Theory. In K. Wentzel \& D. Miele (Eds.), Handbook of motivation at school (pp. 155184). Routledge.

Daumiller, M., Dickhäuser, O., \& Dresel, M. (2019). University instructors' achievement goals for teaching. Journal of Educational Psychology, 111(1), 131-148. https://doi.org/10.1037/edu0000271

Daumiller, M., \& Dresel, M. (2020a). Researchers' achievement goals, work stress, and professional development. Contemporary Educational Psychology, 61, 101843. https://doi.org/10.1016/j.cedpsych.2020.101843

Daumiller, M., \& Dresel, M. (2020b). Teaching and research. International Journal of Educational Research, 99, 101460. https://doi.org/10.1016/j.ijer.2019.08.002

Daumiller, M., Grassinger, R., Dickhäuser, O., \& Dresel, M. (2016). Structure and relationships of university instructors' achievement goals. Frontiers in Psychology, 7(375). https://doi.org/10.3389/fpsyg.2016.00375

Daumiller, M., Grassinger, R., Engelschalk, T., \& Dresel, M. (2021). SEEQ-DE. Diagnostica. Advanced online publication. 1-13. https://doi.org/10.1026/0012-1924/a000274

Daumiller, M., Janke, S., Hein, J., Rinas, R., Dickhäuser, O., \& Dresel, M. (2021). Do teachers' achievement goals and selfefficacy beliefs matter for students' learning experiences?. Learning and Instruction, 101458. https://doi.org/10.1016/j.learninstruc.2021.101458

Daumiller, M., Rinas, R., Hein, J., Janke, S., Dickhäuser, O., \& Dresel, M. (2021). Shifting from face-to-face to online teaching during COVID-19. Computers in Human Behavior, 118, 106677. Advanced online publication. https://doi.org/10.1016/j.chb.2020.106677

Daumiller, M., Siegel, S., \& Dresel, M. (2019). Construction and validation of a Short Multi-disciplinary Research Performance Questionnaire (SMRPQ). Research Evaluation, 28(3), 241252. https://doi.org/10.1093/reseval/rvz009

Daumiller, M., Stupnisky, S., \& Janke, S. (2020). Motivation of higher education faculty. International Journal of Educational Research, 20. https://doi.org/dkdr
DeShon, R. P., \& Gillespie, J. Z. (2005). A motivated action theory account of goal orientation. Journal of Applied Psychology, 90(6), 1096-1127. https://doi.org/c5bk7z

Dickhäuser, O., Janke, S., Daumiller, M., \& Dresel, M. (2021). Motivational school climate and teachers' achievement goal orientations. British Journal of Educational Psychology, 91, 391-408. https://doi.org/10.1111/bjep. 12370

Dweck, C. S. (1986). Motivational processes affecting learning. American Psychologist, 41(10), 1040-1048. https://doi.org/10.1037//0003-066x.41.10.1040

Elliot, A. J. (1999). Approach and avoidance motivation and achievement goals. Educational Psychology, 34 (3), 169-189. https://doi.org/10.1207/s15326985ep3403_3

Elliot, A. J. (2005). A conceptual history of the achievement goal construct. Handbook of competence and motivation, 52-72. Guilford

Elliot, A. J., \& Hulleman, C. S. (2017). Achievement goals. In A. Elliot, C. Dweck, \& D. Yeager (Eds.), Handbook of competence and motivation, 43-60. Guilford.

Elliot, A. J., \& McGregor, H. A. (2001). A $2 \times 2$ achievement goal framework. Journal of Personality and Social Psychology, 80 (3), 501-519. https://doi.org/g9d

Elliot, A. J., Murayama, K., \& Pekrun, R. (2011). A 3 x 2 achievement goal model. Journal of Educational Psychology, 103(3), 632-648. https://doi.org/10.1037/a0023952

Fasching, M. S., Dresel, M., Dickhäuser, O., \& Nitsche, S. (2010). Goal orientations of teacher trainees. Journal for Educational Research Online 2, 9-33. https://doi.org/hbvk

Ferrer, E., \& Mcardle, J. J. (2010). longitudinal modeling of developmental changes in psychological research. Current Directions in Psychological Science 19(3), 149-154.

Festinger, L., (1954). A theory of social comparison processes. Human Relations, 7(2), 117-140. https://doi.org/10.1177/001872675400700202

Folkman, S., Lazarus, R. S., Dunkel-Schetter, C., DeLongis, A., \& Gruen, R. J. (1986). Dynamics of a stressful encounter. Journal of Personality and Social Psychology, 50(5), 992-1003. https://doi.org/10.1037/0022-3514.50.5.992

Freudenberger, H. J. (1974). Staff burn-out. Journal of Social Issues, 30(1), 159-165. https://doi.org/10.1111/j.15404560.1974.tb00706.x

Friedman, I. A. (2000). Burnout in teachers. Journal of Clinical Psychology, 56(5), 595-606. https://doi.org/10.1002/(SICI)10974679(200005)56:5<595::AID-JCLP2>3.0.CO;2-Q

Giacalone, R. A., \& Promislo, M. D. (2014). Handbook of unethical work behavior. Routledge.

Gmelch, W. H. (1993). Coping with faculty stress. Sage.

Grant, H., \& Dweck, C. S. (2003). Clarifying achievement goals and their impact. Journal of Personality and Social Psychology, 85(3), 541-553. https://doi.org/dfq2p4

Hardré, P. L., Beesley, A. D., Miller, R. L., \& Pace, T. M. (2011). Faculty motivation to do research: across disciplines in research-extensive universities. Journal of the Professoriate, 5(1), 35-69.

Han, J., Yin, H., \& Wang, W. (2015). Exploring the relationship between goal orientations for teaching of tertiary teachers and their teaching approaches in China. Asia Pacific Education Review, 16(4), 537-547. https://doi.org/10.1007/s12564-0159392-7

Harrison, A. L., \& Kelly, D. G. (1996). Career satisfaction of physical therapy faculty during their pretenure years. Physical Therapy, 76(11), 1202-1218. https://doi.org/hbvm 
Hattie, J., \& Marsh, H. W. (1996). The relationship between research and teaching: A meta-analysis. Review of Educational Research, 66(4), 507-542. https://doi.org/frxqkk

Hein, J., Daumiller, M., Janke, S., Dresel, M., \& Dickhäuser, O. (2019). How learning time mediates the impact of university scholars' learning goals on professional learning in research and teaching. Learning and Individual Differences, 72, 15-25. https://doi.org/dp36

Hershcovis, M. S., Cameron, A. F., Gervais, L., \& Bozeman, J. (2018). The effects of confrontation and avoidance coping in response to workplace incivility. Journal of Occupational Health Psychology, 23(2), 163-174. https://doi.org/10.1037/ocp0000078

Hulleman, C. S., Schrager, S. M., Bodmann, S. M., \& Harackiewicz, J. M. (2010). A meta-analytic review of achievement goal measures. Psychological Bulletin, 136(3), 422-449. https://doi.org/10.1037/a0018947

Hüther, O., \& Krücken, G. (2018). Higher education in Germany recent developments in an international perspective (Vol. 49). Springer International Publishing.

Janke, S., Daumiller, M., \& Rudert, S. C. (2019). Dark pathways to achievement in science. Social Psychological and Personality Science, 10(6), 783-791. https://doi.org/csd5

Jaksztat, S., Preßler, N., \& Briedis, K. (2012). Comparisons of Study and Work Conditions of PhD Students (Forum Hochschule, Report No 15/2012). Hannover, Germany: HIS. Retrieved from http://www.dzhw.eu/pdf/pub_fh/fh201215.pdf

Janke, S. \& Dickhäuser, O. (2018). A situated process model of vocational achievement goal striving within members of the academic staff at university. Motivation and Emotion, 42(4), 466-481. https://doi.org/10.1007/s11031-017-9657-z

Janssen, O., \& van Yperen, N. (2004). Employees' goal orientations, the quality of leader-member exchange, and the outcomes of job performance and job satisfaction. Academy of Management Journal, 47, 368-384. https://doi.org/10.2307/20159587

Javitz, H., Grimes, T., Hill, D., Rapoport, A., Bell, R., Fecso, R., \& Lehming, R. (2010). U.S. academic scientific publishing. Working paper SRS 11-201. National Science Foundation, Division of Science Resources Statistics.

Jorgensen TD, Pornprasertmanit S, Schoemann AM, Rosseel Y. (2022). semTools: Useful tools for structural equation modeling: R package version 0.5-6. https://CRAN.R-project.org/package $=$ semTools

King, R. B., and McInerney, D. M. (2014). The work avoidance goal construct. Contemporary Educational Psychology, 39(1), 42-58. https://doi.org/10.1016/j.cedpsych.2013.12.002

King, R. B., \& McInerney, D. M. (2016). Do goals lead to outcomes or can it be the other way around. British Journal of Educational Psychology, 68, 296-312. https://doi.org/gg9wpk

Kinman, G., Jones, F., \& Kinman, R. (2006). The well-being of the UK academy, 1998-2004. Quality in Higher Education, 12(1), 15-27. https://doi.org/10.1080/13538320600685081

Landry, R., Lamari, M., \& Amara, N. (2003). The extent and determinants of the utilization of university research in government agencies. Public Administration Review, 63(2), 192205.

Lazowski, R. A., \& Hulleman, C. S. (2016). Motivation interventions in education. Review of Educational Research, 86(2), 602-640. https://doi.org/10.3102/0034654315617832

Lee, M., \& Bong, M. (2016). In their own words. Journal of Educational Psychology, 108(2), 274-294. http://dx.doi.org/10.1037/edu0000048
Little, T. D., Cunningham, W. A., \& Shahar, G. (2002). To parcel or not to parcel. Structural Equation Modeling, 9(2), 151-173. https://doi.org/10.1207/s15328007sem0902_1

Locke, E., \& Latham, G. (1990). A theory of goal setting and task performance. Prentice-Hall.

Lüftenegger M., van de Schoot, R., Schober, B., Finsterwald, M., \& Spiel, C. (2014). Promotion of students' mastery goal orientations. Educational Psychology, 34(4), 451-469. https://doi.org/10.1080/01443410.2013.814189

Marsh, H. W. (1986). Verbal and math self-concepts. American Educational Research Journal, 23(1), 129-149. https://doi.org/10.3102/00028312023001129

Marsh, H.W. (2007). Do university teachers become more effective with experience. Journal of Educational Psychology, 99(4). 775-790. https://doi.org/10.1037/0022-0663.99.4.775

Marsh, H. W., Trautwein, U., Lüdtke, O., Köller, O., \& Baumert, J. (2005). Academic self-concept, interest, grades, and standardized test scores. Child Development, 76(2), 397-416. https://doi.org/10.1111/j.1467-8624.2005.00853.x

Marsh, H. W., \& Hattie, J. (2002). The relation between research productivity and teaching effectiveness. The Journal of Higher Education, 73(5), 603-641. https://doi.org/d5s5q7

Mascret N., Elliot A., Cury F. (2017). The 3 x 2 Achievement Goal Questionnaire for teachers. Educational Psychology, 37(3), 346-361. https://doi.org/10.1080/01443410.2015.1096324

Maslach, C., Jackson, S. E., \& Leiter, M. P. (1996). Maslach burnout inventory manual. CPP.

Maslach, C., \& Leiter, M. P. (2008). Early predictors of job burnout and engagement. Journal of Applied Psychology, 93(3), 498-512. https://doi.org/10.1037/0021-9010.93.3.498

McArdle, P. (2001). Children's play. Child: Care, Health and Development, 27(6), 509-514 https://doi.org/10.1046/j.13652214.2001.00230.x

McGregor, H. A., \& Elliot, A. J. (2002). Achievement goals as predictors of achievement-relevant processes prior to task engagement. Journal of Educational Psychology, 94(2), 381395. https://doi.org/10.1037//0022-0663.94.2.381

McKeachie, W. J. (2007). Good teaching makes a difference. In R. P. Perry \& J. C. Smart (Eds.), The scholarship of teaching and learning in higher education (pp. 457-474). Springer.

Mudrak, J., Zabrodska, K., Kveton, P., Jelinek, M., Blatny, M., Solcova, I., \& Machovcova, K. (2018). Occupational well-being among university faculty. Research in Higher Education, 59(3), 325-348. https://doi.org/10.1007/s11162-017-9467-x

Murayama, K., Elliot, A. J., \& Friedman, R. (2012). Achievement goals. In R. Ryan (Ed.), The oxford handbook of human motivation, (pp. 191-207). Oxford University.

Murayama, K., Elliot, A. J., \& Yamagata, S. (2011). Separation of performance-approach and performance avoidance achievement goals. Journal of Educational Psychology, 103(1), 238256. https://doi.org/10.1037/a0021948

Muthén, L., \& Muthén, B. (2014). Mplus (version 8.1) [Computer Software]. Muthén \& Muthén.

Nicholls, J. G. (1984). Achievement motivation. Psychological Review, 91(3), 328-346. https://doi.org/10.1037//0033295x.91.3.328

Nitsche, S., Dickhäuser, O., Fasching, M. S., \& Dresel, M. (2013). Teachers' professional goal orientations. Learning and Individual Differences, 23, 272-278. https://doi.org/f4m3rf

Papaioannou, A., \& Christodoulidis, T. (2007). A measure of teachers' achievement goals. Educational Psychology, 27(3), 349-361. https://doi.org/10.1080/01443410601104148 
Parker, P. D., Martin, A. J., Colmar, S., \& Liem, G. A. (2012). Teachers' workplace well-being. Teaching and Teacher Education, 28(4), 503-513. https://doi.org/fxjjbn

Pascarella, E. T., \& Terenzini, P. T. (2005). How college affects students. Jossey-Bass Inc.

Payne, S. C., Youngcourt, S. S., \& Beaubien, J. M. (2007). A meta-analytic examination of the goal orientation nomological net. Journal of Applied Psychology, 92(1), 128-150. https://doi.org/10.1037/0021-9010.92.1.128

Perkmann, M., Tartari, V., McKelvey, M., Autio, E., Broström, A., D'Este, P., \& Krabel, S. (2013). Academic engagement and commercialisation. Research Policy, 42(2), 423-442.

Peugh, J. L., \& Enders, C. K. (2004). Missing data in educational research. Review of Educational Research, 74(4), 525-556. https://doi.org/10.3102/00346543074004525

Ponjuan, L., Conley, V. M., \& Trower, C. (2011). Career stage differences in pre-tenure track faculty perceptions of professional and personal relationships with colleagues. The Journal of Higher Education, 82(3), 319-346. https://doi.org/10.1080/00221546.2011.11777204

Praetorius, A.-K., Nitsche, S., Janke, S., Dickhäuser, O., Drexler, K., Fasching, M., \& Dresel, M. (2014). Here today, gone tomorrow. Contemporary Educational Psychology, 39(4), 379387. https://doi.org/10.1016/j.cedpsych.2014.10.002

Retelsdorf, J., Butler, R., Streblow, L., \& Schiefele, U. (2010). Teachers' goal orientations for teaching. Learning and Instruction, 20(1), 30-46. https://doi.org/dj6xhw

Richardson, P. W., Karabenick, S. A., \& Watt, H. M. G. (2014). Teacher motivation. Routledge.

Rinas, R., Dresel, M., Hein, J., Janke, S., Dickhäuser, O., \& Daumiller, M. (2020). Exploring university instructors' achievement goals and discrete emotions. Frontiers in Psychology, 11(1484), 1-15. https://doi.org/10.3389/fpsyg.2020.01484

Robbins, S. B., Lauver, K., Le, H., Davis, D., Langley, R., \& Carlstrom, A. (2004). Do psychosocial and study skill factors predict college outcomes. Psychological Bulletin, 130(2), 261288. https://doi.org/10.1037/0033-2909.130.2.261

Rosseel, Y. (2012). Lavaan: An R package for structural equation modelling. Journal of Statistical Software, 48(2), 1-36. https://doi.org/10.18637/jss.v048.i02

Sabagh, Z., Hall, N. C., \& Saroyan, A. (2018). Antecedents, correlates and consequences of faculty burnout. Educational Research, 60(2), 131-156. https://doi.org/gf5d9c

Salimzadeh, R., Hall N. C., \& Saroyan, A. (2020). stress, emotion regulation, and well-being among canadian faculty members in research-intensive universities. Social Sciences, 9(12), 137. https://doi.org/10.3390/socsci9120227

Salmela-Aro, K., Tolvanen, A., \& Nurmi, J.-E. (2009). Achievement strategies during university studies predict early career burnout and engagement. Journal of Vocational Behavior, 75(2), 162-172. https://doi.org/10.1016/j.jvb.2009.03.009

Senko, C., \& Dawson, B. (2017). Performance-approach goal effects depend on how they are defined. Journal of Educational Psychology, 109(4), 574-598. https://doi.org/gdngfr

Senko, C., Hulleman, C. S., \& Harackiewicz, J. M. (2011). Achievement goal theory at the crossroads. Educational Psychologist, 46(1), 26-47. https://doi.org/bn7gt4

Shin, J., \& Jung, J. (2014). Academics job satisfaction and job stress across countries in the changing academic environments. Higher Education, 67, 603-620. https://doi.org/f5zk6j

Singh, S. N., Mishra, S., \& Kim, D. (1998). Research-related burnout among faculty in higher education. Psychological Reports, 83(2), 463-473. https://doi.org/bksr6q
Smeby, J.-C. (1998). Knowledge production and knowledge transmission. Teaching in Higher Education, 3(1), 5-20. https://doi.org/10.1080/1356215980030101

Sparfeldt, J. R., Brunnemann, N., Wirthwein, L., Buch, S. R., Schult, J., \& Rost, D. H. (2015). General versus specific achievement goals. Learning and Individual Differences, 43, 170-177. https://doi.org/10.1016/j.lindif.2015.08.022

Statistisches Bundesamt [German Federal Statistical Office] (2015). Bildung und Kultur [Education and culture]. Wiesbaden: Statistisches Bundesamt.

Stupnisky, R. H., BrckaLorenz, A., Yuhas, B., \& Guay, F. (2018). Faculty members' motivation for teaching and best practices: Testing a model based on self-determination theory across institution types. Contemporary Educational Psychology, 53, 15-26. https://doi.org/10.1016/j.cedpsych.2018.01.004

Stupnisky, R. H., Hall, N. C., Daniels, L. M., \& Mensah, E. (2017). Testing a model of pretenure faculty members' teaching and research success: Motivation as a mediator of balance, expectations, and collegiality. The Journal of Higher Education, 88(3), 376-400. https://doi.org/10.1080/00221546.2016.1272317

Stupnisky, R. H., Weaver-Hightower, M., \& Kartoshkina, Y. (2015). Exploring and testing predictors of new faculty success. Studies in Higher Education, 40(2), 368-390. https://doi.org/10.1080/03075079.2013.842220

Teichler, U., Arimoto, A., \& Cummings, W. (2013). The changing academic profession. Springer. https://doi.org/10.1007/97894-007-6155-1

Tönjes, B., Dickhäuser, O., \& Kröner, S. (2008). Goal orientation and lack of achievement in teachers. Zeitschrift für pädagogische Psychologie, 22(2), 151-160. https://doi.org/bfswqs

Umbach, P. D., \& Wawrzynski, M. R. (2005). Faculty do matter. Research in Higher Education, 46, 153-184. https://doi.org/10.1007/s11162-004-1598-1

Urdan, T., \& Mestas, M. (2006). The goals behind performance goals. Journal of Educational Psychology, 98(2), 354-365. https://doi.org/10.1037/0022-0663.98.2.354

Van Yperen, N., \& Janssen, O. (2002). Fatigued and dissatisfied or fatigued but satisfied. Academy of Management Journal, 45(6), 1161-1171. https://doi.org/10.2307/3069431

Van Yperen, N., Blaga, M., \& Postmes, T. (2014). A meta-analysis of self-reported achievement goals and nonself-report performance across three achievement domains. PloS ONE, 9(4), 116. https://doi.org/10.1371/journal.pone.0093594

Vansteenkiste, M., Lens, W., Elliot, A., Soenens, B., \& Mouratidis, A. (2014). Moving the achievement goal approach one step forward. Educational Psychologist, 49(3), 153-174. https://doi.org/10.1080/00461520.2014.928598

Weinberg, B. A., Ownen-Smith, J., Rosen, R. J., Schwarz, L., Allen, B., Weiss, R. E., \& Lane, J. (2014). Science funding and short-term economic activity. Science, 344(6179), 41-43.

Widaman, K. F., Ferrer, E., \& Conger, R. D. (2010). Factorial invariance within longitudinal structural equation models. Child Development Perspectives, 4(1), 10-18. https://doi.org/10.1111/j.1750-8606.2009.00110.x

Wigfield, A., \& Koenka, A. C. (2020). Where do we go from here in academic motivation theory and research? Some reflections and recommendations for future work. Contemporary Educational Psychology, 61, 101872. https://doi.org/10.1016/j.cedpsych.2020.101872

Winefield, T., Boyd, C., Saebel, J., \& Pignata, S. (2008). Update on national university stress study. Australian University Review, 50(1), 20-29. 


\section{Footnotes}

${ }^{1}$ The primary purpose of this longitudinal study was to investigate the research questions reported in this manuscript. Unrelated to this, we also included further scales at some of the measurement points for explorative purposes and additional research questions (including scales about [anonymized for peer review]). Using data from the first measurement point and the teaching domain only, we cross-sectionally analyzed associations between [anonymized for peer review; partial overlap with a single variable reported in this manuscript] (Authors, 2021b), [anonymized for peer review; partial overlap with one type of goal reported in this manuscript] (Authors, 2021c), and [anonymized for peer review; partial overlap with four goals and one other variable reported in this manuscript] (Authors, 2021d).

${ }^{2}$ Following Widaman et al. (2010), we tested for measurement invariance over time by estimating confirmatory factor analyses for each construct (e.g., achievement goals for teaching) at all four time points simultaneously. We first established a baseline configural invariance model with equivalent structural model form across the four measurement points, and then fit models in which additional constraints were imposed, equating thresholds and loadings across time (metric invariance), and thresholds, loadings, and item intercepts across time (scalar invariance). All models were estimated using $\mathrm{R}$ with the lavaan package (version 0.6-11; Rosseel et al., 2012), relying on the measEq.syntax from semTools (version 0.5-6; Jorgensen et al., 2022) and the "Wu.Estabrook.2016" strategy to identify model parameters.

${ }^{3}$ We additionally tested whether the relationships between goals, burnout/engagement, and performance differ by comparing the similarity of their correlation matrices based on gender, academic discipline, and career status of the participating faculty members. The results did not provide indications that the relationships differ substantially based on these variables (see supplementary materials). 